\title{
Rankings of extreme and widespread dry and wet events in the Iberian Peninsula between 1901 and 2016
}

\author{
Margarida L. R. Liberato ${ }^{1,2}$, Irene Montero ${ }^{1}$, Célia Gouveia ${ }^{2,3}$, Ana Russo ${ }^{2}$, Alexandre M. Ramos ${ }^{2}$, and \\ Ricardo M. Trigo ${ }^{2}$ \\ ${ }^{1}$ Escola de Ciências e Tecnologia, Universidade de Trás-os-Montes e Alto Douro, \\ UTAD, 5000-801 Vila Real, Portugal \\ ${ }^{2}$ Instituto Dom Luiz, Faculdade de Ciências, Universidade de Lisboa, 1749-016 Lisbon, Portugal \\ ${ }^{3}$ Instituto Português do Mar e da Atmosfera Lisboa, 1749-077 Lisbon, Portugal \\ Correspondence: Margarida L. R. Liberato (mlr@utad.pt)
}

Received: 10 July 2020 - Discussion started: 24 August 2020

Accepted: 11 November 2020 - Published: 19 February 2021

\begin{abstract}
Extensive, long-standing dry and wet episodes are two of the most frequent climatic extreme events in the Iberian Peninsula. Here, a method for ranking regional extremes of persistent, widespread drought and wet events is presented, considering different timescales. The method is based on the multi-scalar Standardized Precipitation Evapotranspiration Index (SPEI) gridded dataset for the Iberian Peninsula. Climatic Research Unit (CRU) data are used to compute the SPEI between 1901 and 2016 by means of a log-logistic probability distribution function. The potential evapotranspiration (PET) is computed using the Penman-Monteith equation. The ranking classification method is based on the assessment of the magnitude of an event, which is obtained after considering both the area affected by the respective dryness or wetness - defined by SPEI values over a certain threshold - and its intensity in each grid point. A sensitivity analysis of the impact of different thresholds used to define dry and wet events is also performed. For both the dry and wet periods, this simple yet robust tool allows for the identification and ranking of well-known regional extremes of persistent, extensive dry and wet periods at different timescales. A comprehensive dataset of rankings of the most extreme, prolonged, widespread dry and wet periods in the Iberian Peninsula is presented for aggregated timescales of 6, 12, 18, and 24 months. Results show that no region in the Iberian Peninsula is more prone to the occurrence of any of these long-term (dry and/or wet) extreme events. Finally, it is highlighted that the application of this methodology to other domains and periods represents an important tool for extensive, long-standing, extreme event assessment worldwide.
\end{abstract}

\section{Introduction}

Similar to other Mediterranean regions, droughts represent one of the most frequent damaging natural hazards in the Iberian Peninsula (Sousa et al., 2011; Lionello et al., 2012; Trigo et al., 2013). In fact, drought events in the Iberian Peninsula (IP) can induce large socio-economic costs, often with widespread negative ecosystem impacts, such as significant losses of agricultural production (e.g. Gouveia et al., 2009), hydro-electric production (e.g. Jerez et al., 2013), or an increasing risk of forest fires (e.g. Amraoui et al., 2013; Liberato et al., 2017). On the other hand, persistent largescale precipitation periods may also be disruptive, often be- ing responsible for high negative socio-economic impacts, such as major floods, landslides, extensive property damage, and even loss of human lives, as described in the literature for wet winters occurring in the IP (e.g. Zêzere et al., 2005; Vicente-Serrano et al., 2011; Sousa and Bastos, 2013).

Drought is a complex phenomenon and differs from other natural hazards in various ways (Wilhite, 1993). Its complexity is linked to the quantification of drought severity, which is usually performed by means of the drought's impacts on different sectors including the economy, ecology, forestry, and agriculture. The identification of drought onset and end as well as the quantification of its spatial extent and intensity 
represents a challenge. The intricacy of this phenomenon is associated with the impossibility of finding a single variable to measure in order to quantify the distinct characteristics of droughts (Vicente-Serrano et al., 2012). Drought is essentially one consequence of an anomalous decrease in precipitation (Palmer, 1965); however, drought intensity varies both with timescale (McKee et al., 1993) and spatial extent (Vicente-Serrano, 2006). The World Meteorological Organization (WMO, 2006) presents a commonly accepted classification of droughts into the following four categories:

1. meteorological drought, which is defined as a precipitation departure from normal over a predefined period of time;

2. agricultural drought, which is defined in terms of the soil water required to support healthy crop growth during the growing season and depends on the precipitation rate and soil characteristics that favour the waterholding capacity;

3. hydrological drought, which usually results from deficiencies in surface and subsurface water supplies, causing reservoirs, lakes, and rivers to dry up as well as a decline in the groundwater level - there is a considerable time lag between precipitation events and their impacts on surface and subsurface components of the hydrologic system, with recovery also being slow due to the long recharge periods;

4. socio-economic drought, which associates droughts with the supply and demand of an economic good that is dependent on precipitation.

In recent years, a special focus has been put on environmental or ecologic droughts when considering long and widespread dry events with strong impacts that may induce changes in natural and managed ecosystems (Crausbay et al., 2017; Vicente-Serrano et al., 2020a).

Drought analysis and monitoring have been conducted using several methodological approaches (e.g. Heim, 2002; Mukherjee et al., 2018). The demanding task of objectively identifying the onset and end of a drought as well as the quantification of drought severity has led to the development of a new set of drought indicators (Vicente-Serrano et al., 2010a): the Palmer Drought Severity Index (PDSI, Palmer, 1965), founded on a soil water balance equation; the Standardized Precipitation Index (SPI; McKee et al., 1993), built using a precipitation probabilistic approach; and the Standardized Precipitation Evapotranspiration Index (SPEI), calculated using precipitation and temperature fields. The main advantage of the SPEI is that it combines the multi-scalar character of the SPI with the ability to include the effects of temperature variability on drought assessment (VicenteSerrano et al., 2010b).

Several studies have shown the relationship between the temporal variability of drought indices and the response of natural ecosystems, such as tree growth (DeSoto et al., 2014), river discharge (Vicente-Serrano and López-Moreno, 2005), crop yields (Vicente-Serrano et al., 2006; Páscoa et al., 2017a), and vegetation activity (Vicente-Serrano et al., 2013; Liberato et al., 2017). The multi-scalar character of the SPI and SPEI indices enables the quantification of different types of droughts, which is something that neither the PDSI nor the so-called self-calibrated PDSI (scPDSI), enhanced to assess droughts over the Mediterranean region (Wells et al., 2004; van der Schrier et al., 2006; Sousa et al., 2011), can provide. Shorter timescales (between 3 and 6 months) can be used to describe agricultural droughts (McKee et al., 1993), as they allow one to monitor the moisture conditions relative to soil and vegetation (Vicente-Serrano, 2006). Medium-length timescales (between 6 and 12 months) are often useful to evaluate hydrological droughts due to their ability to monitor surface water resources (Vicente-Serrano and López-Moreno, 2005). Longer timescales (between 24 and 36 months) indicate longer but less frequent droughts with fewer wet or dry periods (Vicente-Serrano, 2006).

Vicente-Serrano et al. (2012) compared the performance of the above-mentioned drought indices and found that the SPEI and SPI, both computed for different timescales, have an improved ability to capture drought impacts on hydrological, agricultural, and ecological systems. Additionally, the SPEI was the index that best captured the responses of the considered meteorological variables to drought in summer and was more sensitive to global warming (Vicente-Serrano et al., 2010b), as the general (not for a specific species) water balance is reflected in the SPEI computation by the inclusion of the difference between monthly precipitation and the potential evapotranspiration. Moreover, the PDSI, SPEI, and SPI allow for the quantification of both wetness (positive value) and dryness (negative values). The SPI and SPEI are also standardized variables that allow for the detailed analysis of droughts across sites with very different climatology. Over the last few years, both have been used to characterize the dry and wet periods in several regions, namely the SPI for the United States (Wu et al., 2007), Italy (Vergni and Todisco, 2011), and China (Du et al., 2013), and the SPEI for the Czech Republic (Potopová et al., 2015), central Europe (Spinoni et al., 2013), China (Tao et al., 2015), and Vietnam (Stojanovic et al., 2020). Several authors have performed drought characterization and the assessment of impacts, namely on vegetation dynamics (Gouveia et al., 2016; Liberato et al., 2017) and on crop production and yield (Páscoa et al., 2017a, b; Ribeiro et al., 2019a). The SPEI and SPI were used to identify drought severity and intensity, and both indices can identify the severest and longest events. Despite the recent issues raised due to the uncertainties on atmospheric evaporative demand (AED) computation (Domínguez-Castro et al., 2019; Vicente-Serrano et al., 2020b), some works have highlighted the ability of the SPEI to identify tendencies towards dryer conditions in the 
IP (Vicente-Serrano et al., 2014; Spinoni et al., 2015; Coll et al., 2016; Páscoa et al., 2017b).

The characterization of wet and dry periods in the IP becomes extremely important as the region is frequently affected by extreme wet and dry events (Vicente-Serrano et al., 2011; Ramos et al., 2014, 2016; González-Hidalgo et al., 2018; Domínguez-Castro et al., 2019; Sorí et al., 2020; Vicente-Serrano et al., 2020b) and, consequently, by their impacts on several systems (Liberato, 2014; Trigo et al., 2016; Liberato et al., 2017; Pereira et al., 2018; Ribeiro et al., 2019a, b). The significant damage from these events justifies the use of several timescales in the analyses, ranging from 6 to 24 months. Thus, it is important to carry out the assessment of the extreme wet and dry periods affecting an extensive area of IP at longer timescales. Therefore, this work has the main goal of ranking the most severe, widespread dry and wet periods in Iberia at several timescales as well as analysing their evolution over time from the beginning of the 20th century to present.

In summary, the main goals of this paper are to

i present a tool that allows for the identification of regional extremes of persistent, widespread dry and wet periods at different timescales;

ii build a comprehensive dataset of rankings of the most extreme, prolonged, widespread drought and wet periods in Iberia, for timescales of 6, 12, 18 and 24 months, spanning the period from 1901 to 2016, using the multiscalar SPEI gridded dataset with a regular resolution of $0.5^{\circ}$.

It should be highlighted that the novelty of this study is two-fold: on the one hand, the methodology introduced by Ramos et al. (2014) for precipitation, which is adapted here to build rankings of extreme and widespread dry and wet events, accounting for several timescales, is applied. This approach has the advantage of being easily scalable to other domains and indices. On the other hand, this article provides evidence of the importance of assessing extreme events considering both the intensity and spatial extent. Developing a ranking system is fundamental for future research on (dry and wet) extremes: from an impact study perspective, it is important for the development of future risk assessments, but it is also important to understand the physical mechanisms behind each of these events to enable the attribution of these events to climate (natural or forced) variability or to climate change.

\section{Data and methodology}

\subsection{SPEI datasets}

The Climatic Research Unit (CRU) TS4.01 high-resolution gridded data for the 1901-2016 period are used in this study to obtain the SPEI time series. The CRU TS4.01 dataset includes month-by-month time series that are calculated on high-resolution $\left(0.5 \times 0.5^{\circ}\right)$ grids based on an archive of monthly average daily data provided by more than 4000 weather stations distributed around the world (Jones and Harris, 2013). At this resolution the study region of the IP corresponds to a square of $30 \times 30$ grid pixels.

The CRU TS43.01 variables include cloud cover, diurnal temperature range, frost day frequency, potential evapotranspiration (PET), precipitation, daily mean temperature, monthly average daily maximum and minimum temperature, vapour pressure, and wet-day frequency. Thus, this dataset is very suitable for the study of climate variability and for drought analysis. The CRU potential evapotranspiration (PET) used is based on the Penman-Monteith equation. This method is considered to be the standard procedure for computing PET by several international institutions, such as the Food and Agriculture Organization of the United Nations (FAO), the International Commission on Irrigation and Drainage (ICID), and the American Society of Civil Engineers (ASCE). The log-logistic probability distribution is also used to fit the SPEI, and the L-moment method is used for the parameter estimation. This formulation allows for a very good fit to the series of differences between precipitation and PET (Vicente-Serrano et al., 2010b).

SPEI values mostly range between -2.5 and 2.5 , corresponding to exceedance probabilities of approximately 0.006 and 0.994 respectively, although the theoretical limits are $(-\infty, \infty)$. The severe dry and wet events were selected based on a SPEI threshold of -1.28 and 1.28 respectively, which corresponds to approximately $10 \%$ of the extreme cases according to the probability distribution function (Agnew, 2000).

The use of a long-term period (116 years) allows for the identification of spatial patterns of droughts and wet periods over the IP; this increases the knowledge on the most intense and wide-ranging extremes in the region as well as their temporal variability from a climatic perspective while also classifying the extreme events and the wet or droughtprone areas.

The usage of datasets that include data prior to 1950 is widely discussed (e.g. Sousa et al., 2011). Nevertheless, it should be recognized that the CRU TS 4.01 dataset originates from thousands of stations dispersed non-randomly, with higher densities at mid-latitudes (Macias-Fauria et al., 2014). As the analysis of the present work is constrained to the IP, which includes a relatively homogeneous number of stations, we consider that the quality of the data ensures a robust analysis (keeping in mind that the number of stations used has varied over time). Supplementary information on stations' availability and on the interpolation methods used is provided in New et al. (2000) and Mitchell and Jones (2005). With respect to the smaller number of meteorological stations available until the 1950s in comparison with the remaining period, Harris et al. (2013) showed that these pre- 
cipitation and temperature time series are highly correlated with other datasets. Moreover, this database has been used by Russo et al. (2015) and Páscoa et al. (2017a), who attained good results in the IP, including the earlier years (Páscoa et al., 2017a, b).

\subsection{Ranking extreme widespread drought and wet events}

As previously mentioned, one of the main aims of this study is to characterize and rank the most extreme, widespread drought (wet) events. Thus, only severe drought (wet) events should be selected based on a SPEI threshold of -1.28 $(+1.28)$, which corresponds to $10 \%$ of extreme cases according to the probability distribution function. This procedure allows for the selection of a dataset of extreme drought (wet) events for each grid point that is then analysed. Following the approach used for daily extreme precipitation in Iberia (Ramos et al., 2014), we adapt it for a monthly dataset. Thus, the spatial extent of the events is assessed for each month of the dataset and for each timescale by multiplying

- the mean value of the SPEI for all of the grid points selected from the threshold criteria above - i.e. below (above) the threshold of $-1.28(+1.28)$;

- the area (hereafter $\mathrm{A}$, in percent) affected by that extreme value.

It is worth mentioning that the sensitivity of this ranking to the chosen threshold has also been assessed. Several tests have been performed, namely by using a less restrictive value $(-0.83$ and +0.83 for moderate dry and wet events respectively). As expected, these changes imply that the absolute mean values are reduced while the area increases. Final results do not change the top rank of the most extreme events significantly, even though some years appear in different rank order.

This methodology may be applied to all months of all timescales as well as to different domains. This would implicate a very large number $(288=12$ months $\times 24$ timescales $)$ of different rankings for each domain. For the sake of clarity and in view of the physical interpretation of extreme events occurring in the IP (Fig. 1), the analysis is performed for specific months for each of the four timescales $(6,12,18$, and 24 months); the reason for this is outlined in the following. For shorter timescales, the 6-month timescale, which allows for the description of agricultural droughts (McKee et al., 1993), is assessed for the month of March. This represents the winter (October to March) drought or wet period over the IP. The 12-month timescale is represented by the values obtained for the month of September, thereby encompassing the hydrological year, which is particularly suitable for monitoring surface water resources (Vicente-Serrano and López-Moreno, 2005). Additionally, the longer timescales 18 months for March and 24 months for September - enable

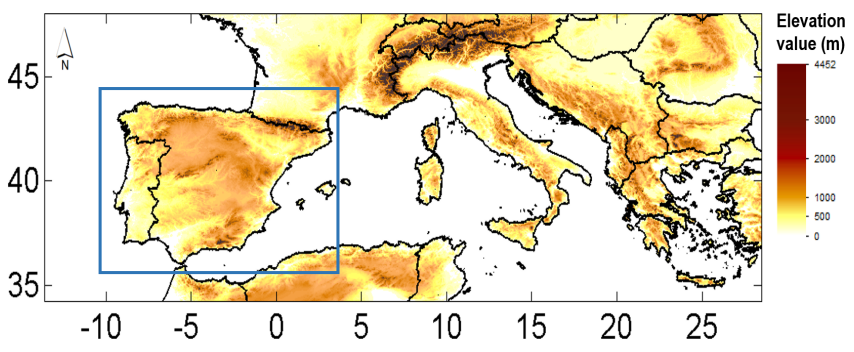

Figure 1. The Iberian Peninsula (blue box) in the Mediterranean region. Colour represents elevation (in metres).

the study of longer, multi-annual, less frequent droughts. It should be noted that results obtained for longer timescales (18 and 24 months) should be looked at very carefully due to the autoregressive character of the SPEI (or SPI).

The rank index, $|\mathrm{R}|$, is used to rank the extensive dry (wet) events in the IP, considering not only the severity of the extended winter (October to March) drought (wet) but also its spatial extent which may be evaluated by the affected area (A, in percent) of the IP that has SPEI values surpassing the chosen threshold - in this case only the most severe and extreme $10 \%$ of events, characterized by SPEI $<-1.28$ $($ SPEI $>1.28)$ at each grid point. The mean SPEI value that characterizes the drought (wet) event is omitted in the tables for the sake of simplicity, as it may be easily obtained from the quotient between $|\mathrm{R}|$ and $\mathrm{A}$ - negative (positive) for dry (wet) events.

\section{Extensive extreme droughts during the 1901-2016 period}

The methodology described in the previous section has been applied successively to the several datasets, timescales, and domains considered, thereby generating several different ranking lists. Here, the SPEI was applied with the main purpose of identifying the major extensive, extreme droughts that affected the IP while illustrating the relevance of the method. In this section the 10 most extreme events (top 10) for each timescale are presented in Table 1, the six major droughts (top 6) are shown in Fig. 2, and some examples are discussed in detail.

\subsection{Extreme agricultural droughts (6-month timescale)}

Table 1 shows the top 10 absolute final rank index, $|\mathrm{R}|$, for the 6-month timescale obtained for March. As expected, the top 10 episodes identified in Table 1 for the 6-month timescale (March) correspond to well-known droughts that had high negative impacts on the IP. The top 1 (mean SPEI06 of -2.00) is the well-known drought episode of the 20112012 winter (Trigo et al., 2013). The extensive spatial extent of these droughts is clearly illustrated in the first column of Fig. 2, which shows the grid points that, in March of the cor- 
Table 1. The 10 most dry extreme events (top 10) for each timescale. Absolute final rank index, $|\mathrm{R}|$, for the 6-month timescale obtained for March (SPEI 06), for the 12-month timescale obtained for September (SPEI 12), for the 18-month timescale obtained for March (SPEI 18), and for the 24-month timescale obtained for September (SPEI 24). "A" represents the area (in percent) where the respective index is below the -1.28 threshold.

\begin{tabular}{lrrr|rrr|rr|rr|rr}
\hline \multirow{2}{*}{ Rank } & \multicolumn{3}{c|}{ SPEI 06 (March) } & \multicolumn{2}{c|}{ SPEI 12 (September) } & \multicolumn{2}{c|}{ SPEI 18 (March) } & \multicolumn{2}{c}{ SPEI 24 (September) } \\
\cline { 2 - 12 } No. & Year & A (\%) & $|\mathrm{R}|$ & Year & A $(\%)$ & $|\mathrm{R}|$ & Year & A (\%) & $|\mathrm{R}|$ & Year & A $(\%)$ & $|\mathrm{R}|$ \\
\hline 1 & 2012 & 73.86 & 147.47 & 2005 & 73.30 & 158.96 & 2012 & 78.98 & 172.34 & 2005 & 79.83 & 177.06 \\
2 & 2000 & 69.32 & 129.45 & 2012 & 76.14 & 131.91 & 2005 & 71.59 & 114.41 & 2012 & 79.55 & 166.70 \\
3 & 1983 & 56.25 & 91.50 & 2009 & 68.47 & 126.58 & 1949 & 62.22 & 109.02 & 2015 & 67.90 & 116.68 \\
4 & 1907 & 54.55 & 87.60 & 2015 & 67.33 & 122.75 & 2008 & 62.50 & 100.84 & 1945 & 61.65 & 115.75 \\
5 & 1961 & 55.97 & 85.96 & 2016 & 60.51 & 114.43 & 1992 & 53.13 & 99.07 & 1995 & 63.64 & 109.46 \\
6 & 1992 & 51.14 & 85.96 & 1945 & 61.65 & 112.38 & 1981 & 49.43 & 78.94 & 2016 & 52.56 & 96.22 \\
7 & 1945 & 49.15 & 75.89 & 2011 & 63.35 & 108.24 & 1995 & 39.20 & 72.32 & 2009 & 49.72 & 86.08 \\
8 & 1993 & 44.89 & 72.21 & 2003 & 53.13 & 90.60 & 2000 & 40.06 & 61.41 & 2011 & 37.22 & 62.68 \\
9 & 1995 & 40.63 & 71.10 & 1990 & 53.69 & 85.52 & 2016 & 32.95 & 59.81 & 2014 & 35.80 & 58.90 \\
10 & 1944 & 44.60 & 68.71 & 1995 & 39.77 & 59.18 & 1999 & 38.64 & 57.09 & 2006 & 34.94 & 50.10 \\
\hline
\end{tabular}

responding year, had SPEI values lower than -1.28 (at the 6month timescale). Another notable aspect of these results is that the most extreme episodes also correspond to events that affected a larger area. In fact, during the top 6 events, represented in the first column of Fig. 2, more than $50 \%$ of the IP area suffered from severe or extreme drought. Additionally, as seen from the first column of Fig. 2, there is no evidence of the existence of a particular region in the IP that might be more prone to extreme or severe agricultural droughts, even though there is prevalence on the western sectors of the IP, especially affecting Portugal.

\subsection{Extreme hydrological droughts (12-month timescale)}

As previously mentioned, the 12-month timescale SPEI for the month of September is used here to assess severe and extreme hydrological (October of year $n-1$ to September of year $n$ ) droughts, which represent important negative impacts on the water resources. The analysis of Table 1 shows that most of the top 10 episodes of agricultural droughts (SPEI06) developed into extreme hydrological droughts (SPEI12) that are also in the respective top 10. In fact, the 2004-2005 (top no. 15) drought event (García-Herrera et al., 2007), which is classified here as the 15th most extreme agricultural drought in the IP (mean SPEI06 of -1.48 over circa $32 \%$ of Iberia), is now top no. 1 (mean SPEI12 of -2.17) on the 12-month timescale, with more than $73 \%$ of the IP suffering severe or extreme drought (second column of Fig. 2); the 2012 (SPEI06, top no. 1) drought is now the top no. 2 (mean SPEI12 of -1.73) on the 12-month timescale, with more than $76 \%$ of the IP suffering severe or extreme drought (Fig. 2); the 1945 (SPEI06, top no. 7) drought is now top no. 6 (mean SPEI12 of -1.82) on the 12-month timescale, with almost $62 \%$ of the IP suffering severe or extreme drought (Fig. 2). Naturally, some events can drop even more significantly in the ranking; thus, the 2000 (top no. 2) drought is now top no. 19 (mean SPEI12 of -1.59) on the 12-month timescale, with only $17 \%$ of the IP suffering severe or extreme drought. From Table 1, it is noticeable that the spatial extent of the most extreme hydrological droughts is generally larger. The area of 2012 (SPEI06, top no. 1) is $74 \%$, while its area (SPEI12, top no. 2) increases to 76\%; and the area of 1945 (SPEI06, top no. 7 ) increases from $49 \%$ to $62 \%$. On the contrary, the disappearance of some events from the top 10 is generally due to a reduction in the affected area. This decrease in the affected area is evident from inspection of the second column of Fig. 2.

\subsection{Extreme persistent droughts (18- and 24-month timescales)}

The same methodology has also been applied to study longer, persistent extreme droughts. As mentioned above, the 18month timescale SPEI for the month of March (third column of Fig. 2) and the 24-month timescale SPEI for the month of September (fourth column of Fig. 2) are used to assess severe and extreme persistent droughts, which represent major negative societal impacts. The analysis of Table 1 shows that most of the top 10 episodes of extensive agricultural and hydrological droughts in the IP developed into extreme persistent droughts which are also in the top 10 on 18and 24-month timescales. Examples are the 2004-2005 and 2011-2012 droughts, alternating as top no. 1 and top no. 2 on both timescales (A18 $=72 \%$ and $\mathrm{A} 24=80 \%$ for 2005 ; $\mathrm{A} 18=79 \%$ and $\mathrm{A} 24=80 \%$ for 2012), the 2015-2016 (top no. $9, \mathrm{~A} 18=33 \%$, top no. $6, \mathrm{~A} 24=53 \%$ ) and the 1995 (top no. $7, \mathrm{~A} 18=39 \%$, top no. 5 , A $24=64 \%$ ) droughts.

In summary, when applying this method that was developed to take two factors into consideration, namely the area of influence of the drought (given by SPEI values below a certain threshold) and the severity of the episode (given by the mean values of the SPEI below the chosen threshold), the 


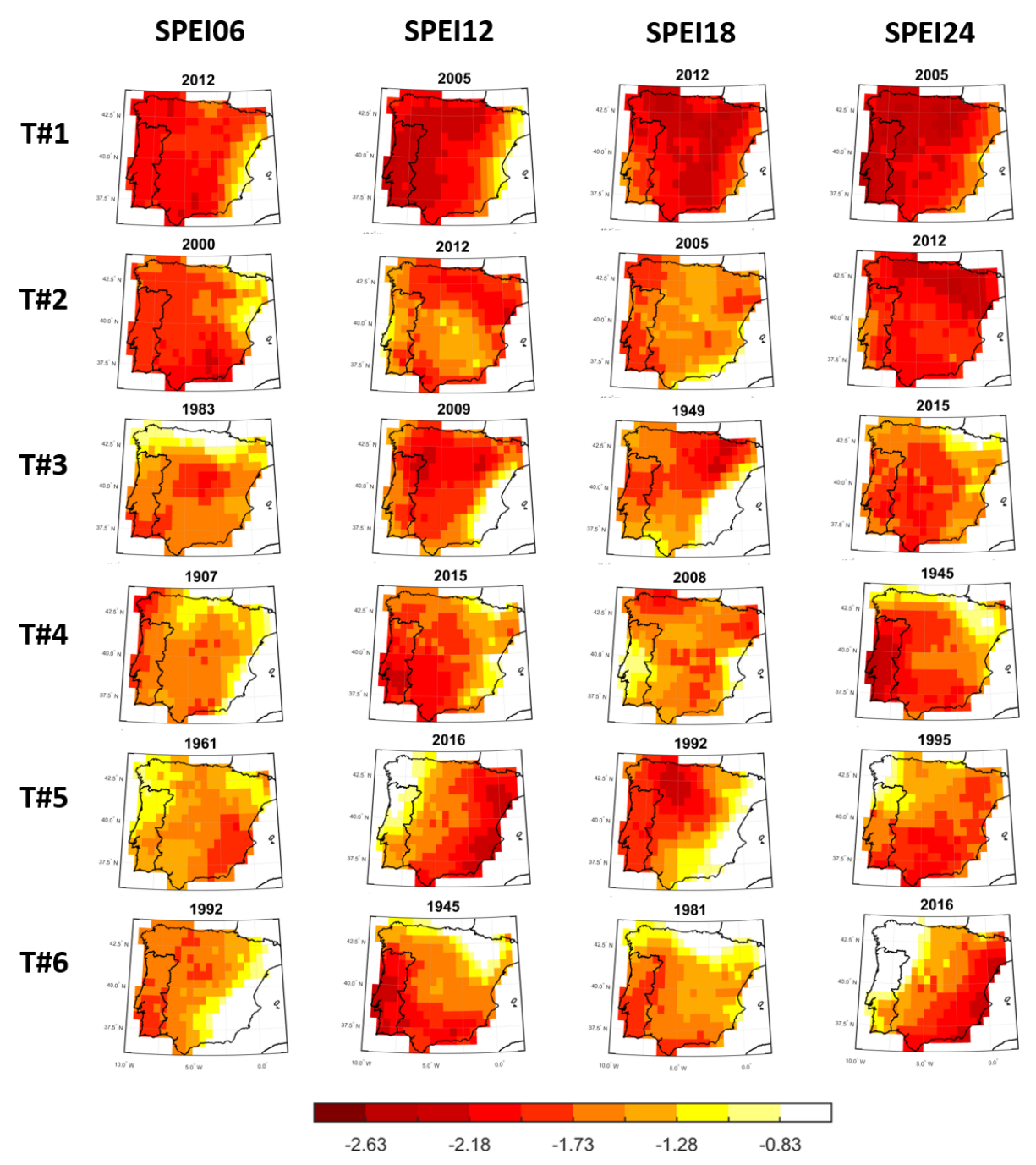

Figure 2. The top 6 drought events in the Iberian Peninsula domain for the 6-month timescale SPEI for March (2012, 2000, 1983, 1907, 1961, and 1992; first column), the 12-month timescale SPEI for September (2005, 2012, 2009, 2015, 2016, and 1945; second column), the 18-month timescale SPEI for March (2012, 2005, 1949, 2008, 1992, and 1981; third column), and the 24-month timescale SPEI for September $(2005,2012,2015,1945,1995$, and 2016; fourth column).

well-known widespread, extreme droughts occurring in the IP are correctly hierarchized at the different timescales.

\subsection{Frequency of widespread droughts}

Until this point, the method developed has only been applied to the severe and extreme droughts by considering, for each month, the -1.28 threshold (i.e. pixels with SPEI $<-1.28$ ). As it is important to evaluate the sensitivity of the results to this criterion, similar rankings have been built with the -0.83 threshold for the same timescales. Therefore, these new ranking lists correspond to widespread moderate, severe, or extreme droughts. As expected, when relaxing the severity criterion (from -1.28 to -0.83), the mean values of SPEI decrease, whereas the area affected by the droughts increases. Consequently, the years in the top 10 ranking lists remain mostly the same, although they may occupy a different ranking order. Exceptions are top no. 9 for SPEI06, top no. 10 for SPEI18, and top no. 8 and top no. 10 for SPEI24, which are no longer classified on the 10 most extreme episodes. Unsurprisingly, the SPEI06 ranking list, corresponding to agricultural droughts, is the most sensitive to the threshold choice. The consistency among ranking lists is evident in the analysis of the time evolution of the ranking index obtained from the SPEI as depicted by the different timescales considered (Fig. 3). In this figure, the red lines correspond to the ranking indices obtained from only severe and extreme droughts (threshold -1.28), and the blue lines represent the ranking indices obtained from the most extreme droughts (threshold -1.65 ). The correlation for each pair of lists is between 0.962 and 0.966 . 

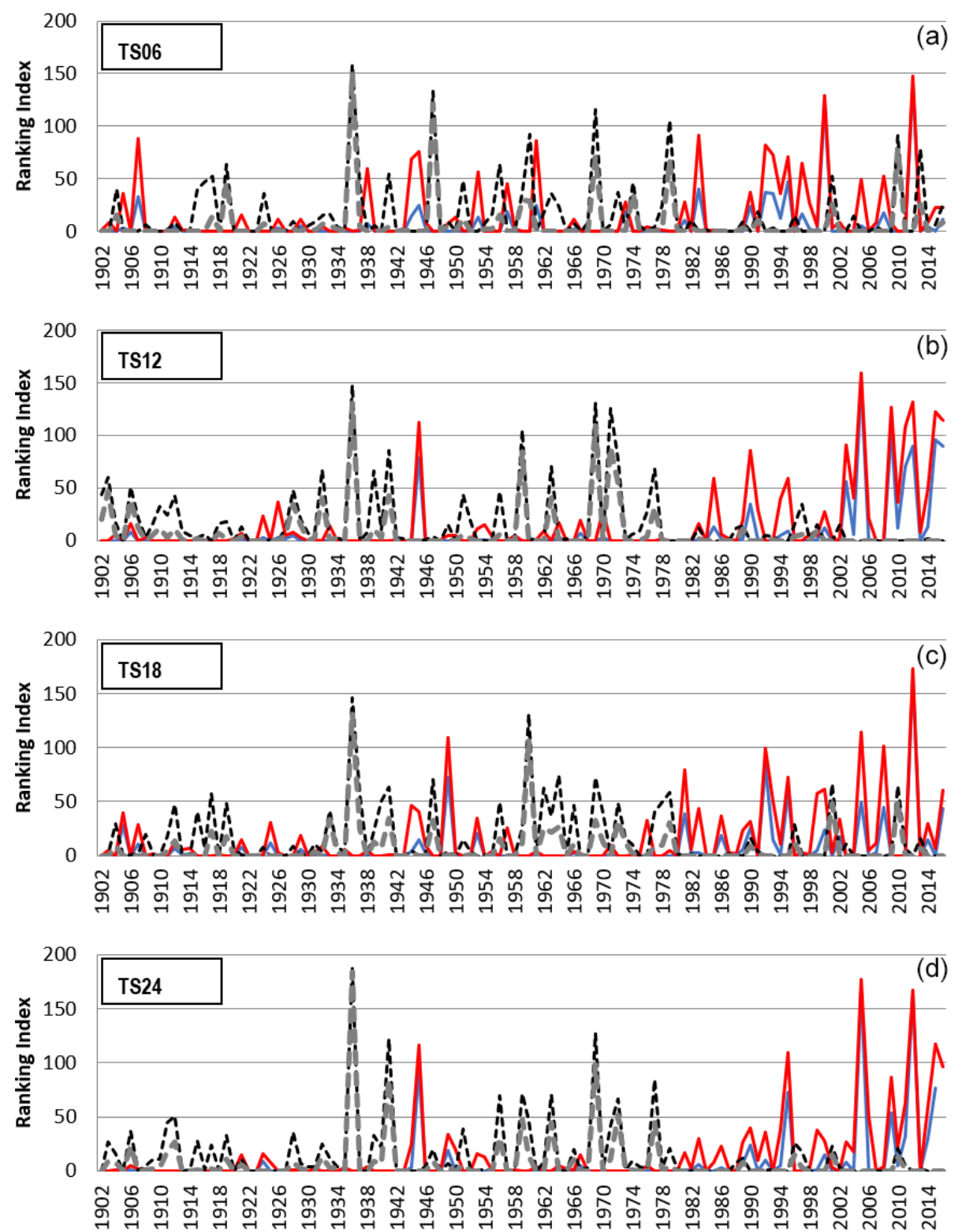

Figure 3. Time evolution of (a) agricultural droughts (ranking index obtained from March SPEI at the 6-month timescale), (b) hydrological droughts (ranking index obtained from September SPEI at the 12-month timescale), and (c-d) longer, persistent (ranking indices obtained from March SPEI at the 18-month timescale $\mathbf{c}$ and September at the 24-month timescale d) droughts. The red lines correspond to the ranking indices obtained from severe and extreme droughts (threshold -1.28); the blue lines represent the ranking indices obtained from the most extreme droughts (threshold -1.65). The black and grey lines represent the analogous time evolution of the moist ranking index obtained for each of the timescales (threshold 1.28, black, and 1.65, grey).

Figures 3 and 4 summarize the above-mentioned results well:

- Most widespread agricultural droughts have correspondence on longer timescales. Thus, the most extreme extensive agricultural droughts evolve into hydrological and more persistent extreme droughts.

- There is a clear temporal clustering of most extreme drought episodes, particularly with a large concentra- tion between 1943 and 1957 and a second group after 1975. This is valid independently of the considered timescales.

- The difference between the red curve (moderate, severe, or extreme) and the blue curve (only severe or extreme episodes) is reduced during the most extreme drought episodes. 

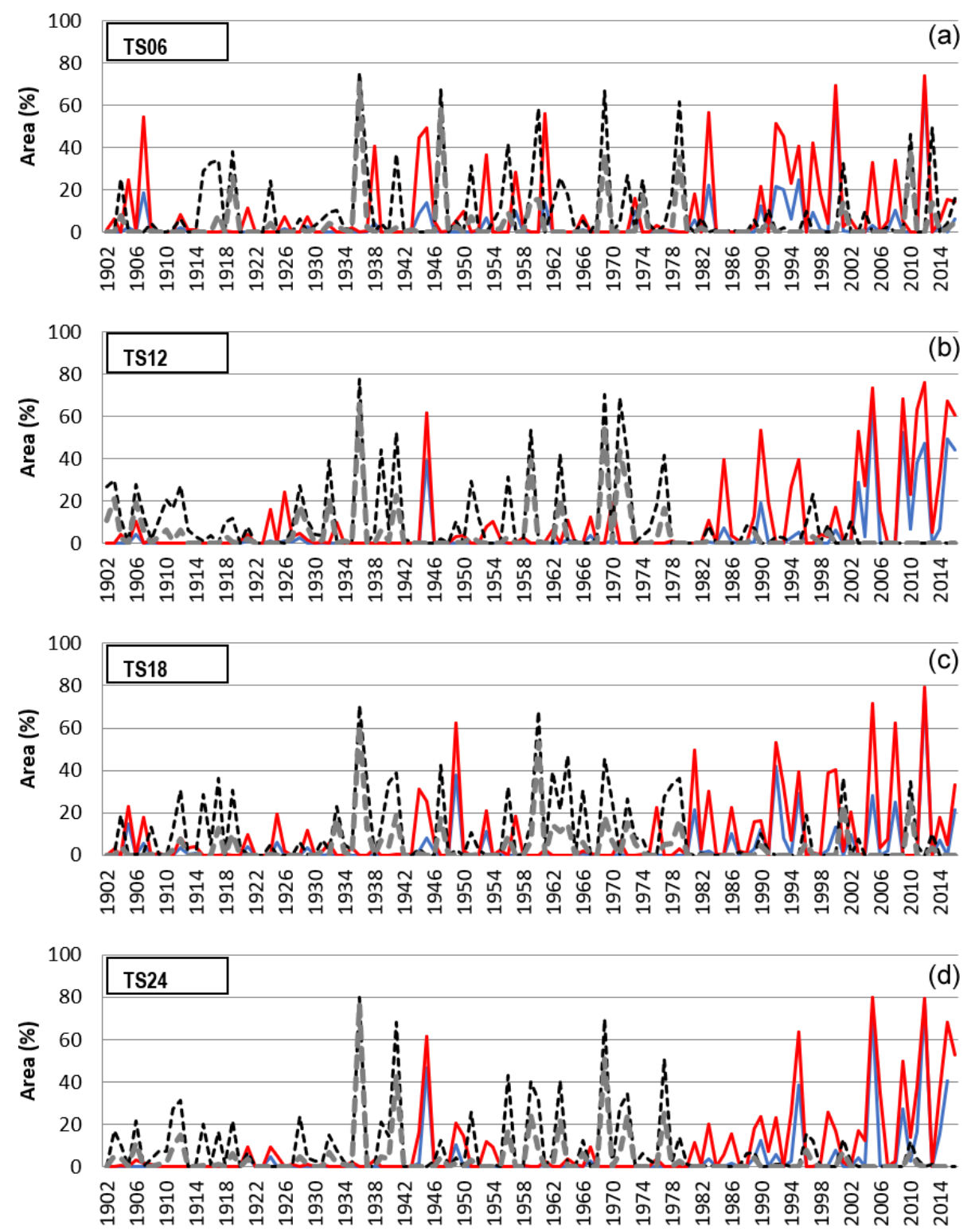

Figure 4. Similar to Fig. 3 but for area (A, in percent), for the four timescales.

- Most moderate drought episodes are coincident with severe or extreme drought, even though each moderate drought episode usually has a smaller index - and thus a smaller extension, as confirmed in Fig. 4.

- The frequency of extensive episodes is almost the same at all of the timescales considered - widespread moderate drought episodes, even if they have smaller extent (Fig. 4), occur at the four timescales analysed.

Individual, recent, extreme wet and drought events are well known in the IP - for example, the outstanding 20042005 drought (Garcia-Herrera et al., 2007), the record winter drought of 2011-2012 (Trigo et al., 2013), or the 20092010 extreme winter precipitation event (Vicente-Serrano et al., 2011). Therefore, severe and long drought events are frequent in the IP and have been becoming even more severe over the last decades (Trigo et al., 2013). This increasing severity is accompanied by an increased tendency toward dryness and a decrease in vegetation cover, due to the higher atmospheric evaporative demand (Vicente-Serrano et al., 2012, 2014). This is reflected on the higher trends of SPEI than for SPI in the IP.

Páscoa et al. (2017b) evaluated the long-term evolution of droughts in the IP using both the SPEI and SPI at 12-month timescales computed using data from the CRU database for the period from 1901 to 2012 and for the three following subperiods: 1901-1937, 1938-1974, and 1975-2012. Both indicators agree with respect to identifying the most intense 


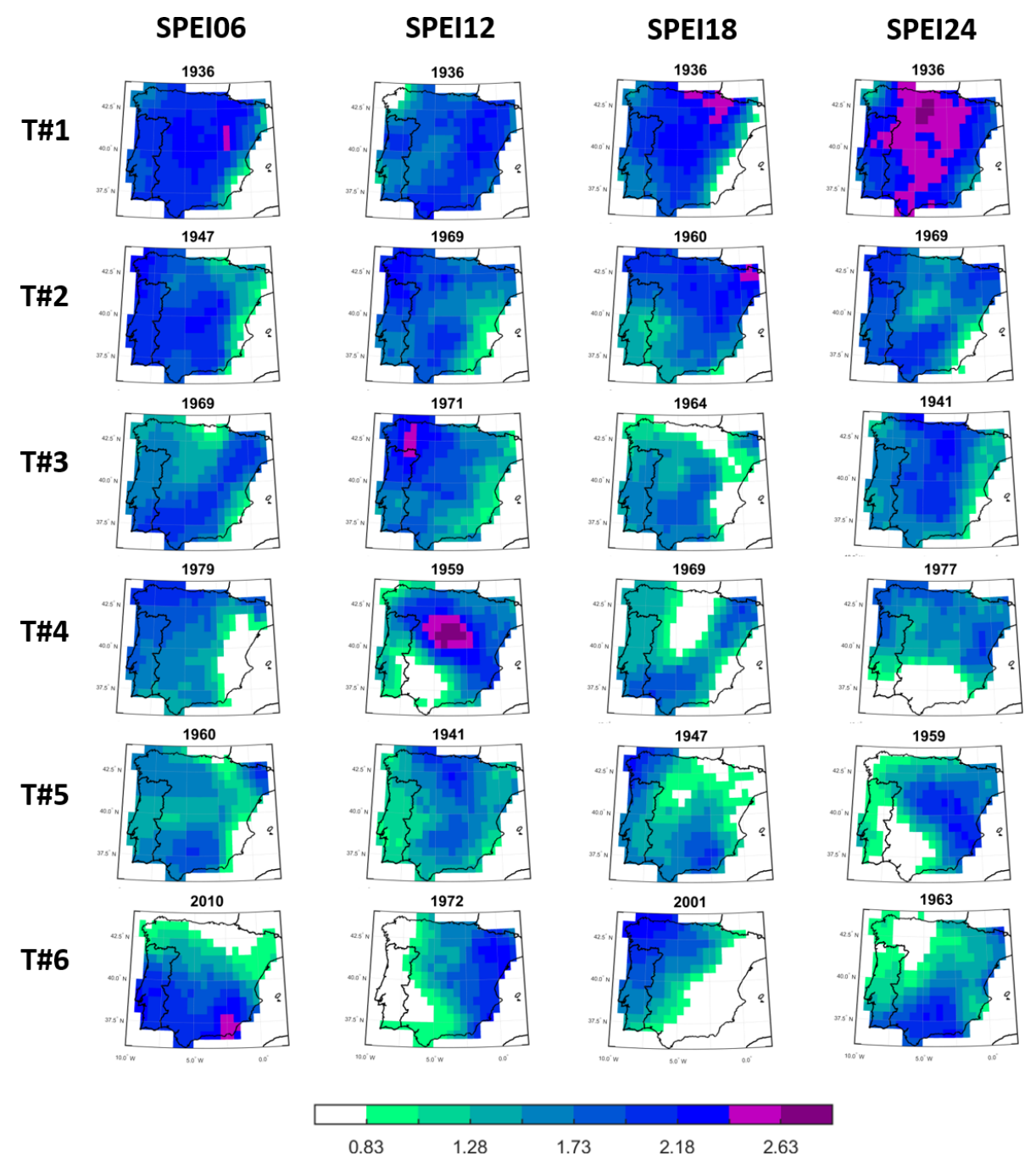

Figure 5. The top 6 wet events in the Iberian Peninsula domain for the 6-month timescale SPEI for March (first column), the 12-month timescale SPEI for September (second column), the 18-month timescale SPEI for March (third column), and the 24-month timescale SPEI for September (fourth column).

and longer dry episodes during the 1940s, 1950s and after the 1980 shey also identify the 1960 s and 1970 s as predominantly wet periods, whereas the 1910s and 1930s showed shorter wet and dry periods (Vicente-Serrano et al., 2006). Moreover, the recent 2004-2005 and 2011-2012 extreme drought events are clearly evident in all indices used (Páscoa et al., 2017b). These were also highlighted in the works by González-Hidalgo et al. (2018), Domínguez-Castro et al. (2019), and Vicente-Serrano et al. (2020b).

\section{Extensive extreme wet events during the 1901-2016 period}

Similar analysis is now performed for the widespread, moist periods occurring in the IP during the 1901-2012 period. Table 2 shows the top 10 absolute final rank index $|\mathrm{R}|$ used for ranking the extensive wet events in the IP for the four considered timescales. Figure 5 shows the grid points that had SPEI values higher than +1.28 for the wet top 6 events (at the four considered timescales). As previously stated, this index considers not only the severity of the wet episodes but also their spatial extent, which may be evaluated by the affected area (A, in percent) of the IP that has SPEI values surpassing the chosen threshold (in this case, only $10 \%$ of the most severe and extreme events, characterized by SPEI $>+1.28$ at each grid point). As in Table 1, the mean SPEI value which characterizes the wet event is omitted from Table 2 for the sake of simplicity, as it may be easily obtained from the quotient between $|\mathrm{R}|$ and $\mathrm{A}$ (which is always positive for wet events).

The first noticeable result is that the method performs equally well when we build the ranking lists for extensive, extreme moist events; therefore, analogous statements can be raised concerning the top rank tables. As expected, some 
Table 2. The 10 most wet extreme events (top 10) for each timescale. Absolute final rank index $|\mathrm{R}|$ for the 6-month timescale obtained for March (SPEI 06), for the 12-month timescale obtained for September (SPEI 12), for the 18-month timescale obtained for March (SPEI 18), and for the 24-month timescale obtained for September (SPEI 24). "A" represents the area (in percent) where the respective index is above the 1.28 threshold.

\begin{tabular}{lcrr|rrr|rrr|rr|rr}
\hline Rank & \multicolumn{3}{c|}{ SPEI 06 (March) } & \multicolumn{2}{c|}{ SPEI 12 (September) } & \multicolumn{2}{c|}{ SPEI 18 (March) } & \multicolumn{2}{c}{ SPEI 24 (September) } \\
\hline No. & Year & A $(\%)$ & $|\mathrm{R}|$ & Year & A $(\%)$ & $|\mathrm{R}|$ & Year & A (\%) & $|\mathrm{R}|$ & Year & A $(\%)$ & $|\mathrm{R}|$ \\
\hline 1 & 1936 & 75.57 & 158.31 & 1936 & 77.56 & 148.42 & 1936 & 70.74 & 146.13 & 1936 & 80.11 & 188.77 \\
2 & 1947 & 67.05 & 133.47 & 1969 & 70.45 & 130.97 & 1960 & 68.18 & 130.72 & 1969 & 69.89 & 126.87 \\
3 & 1969 & 66.48 & 115.28 & 1971 & 68.75 & 125.54 & 1964 & 47.16 & 73.84 & 1941 & 67.90 & 121.97 \\
4 & 1979 & 61.36 & 105.84 & 1959 & 53.69 & 105.41 & 1969 & 45.45 & 71.95 & 1977 & 50.85 & 83.91 \\
5 & 1960 & 58.52 & 91.95 & 1941 & 52.27 & 85.30 & 1947 & 42.33 & 69.82 & 1959 & 39.77 & 71.10 \\
6 & 2010 & 46.02 & 91.31 & 1972 & 42.05 & 77.59 & 2001 & 36.08 & 66.47 & 1963 & 40.63 & 70.86 \\
7 & 2013 & 49.43 & 77.62 & 1963 & 42.05 & 70.42 & 2010 & 34.66 & 64.19 & 1956 & 43.18 & 69.29 \\
8 & 1919 & 38.07 & 63.48 & 1977 & 42.05 & 67.90 & 1941 & 38.64 & 63.49 & 1972 & 34.38 & 66.91 \\
9 & 1956 & 41.76 & 63.18 & 1932 & 39.20 & 66.83 & 1962 & 39.20 & 62.03 & 1912 & 31.53 & 51.05 \\
10 & 1941 & 36.93 & 54.10 & 1939 & 44.03 & 65.90 & 1979 & 36.08 & 58.47 & 1960 & 31.25 & 46.89 \\
\hline
\end{tabular}

of the events represented on the top 10 correspond to wellknown very moist periods in the IP, such as the 2010 winter (Vicente-Serrano et al., 2011; Liberato et al., 2013) and the 2001 winter (Sousa et al., 2011; Ramos et al., 2014, 2017).

The consistency among ranking lists is also evident from the analysis of the time evolution of the ranking index obtained from the SPEI at all timescales considered (Figs. 3, 4). Black dashed lines correspond to the ranking indices obtained from only severe and extreme wet events (threshold +1.28 ), and grey dashed lines represent the ranking indices obtained from the most extreme moist periods (threshold +1.65 ). The correlation between time series relative to each pair of lists is very high, ranging between 0.950 and 0.965. As expected, the extensive droughts are anticorrelated with the extensive wet periods - values ranging between -0.243 and -0.297 (significant at the $1.08 \%$ level).

Figure 4 summarizes the abovementioned results well:

- Most widespread wet events have correspondence on longer timescales.

- Most extreme wet episodes occurred between 1936 and 1941 and between 1959 and 1979 at all timescales (e.g. Páscoa et al., 2017b).

- In the most extreme cases, the difference between moderate, severe, or extreme, and only severe or extreme episodes is reduced.

- Most widespread moderate wet episodes are anticorrelated with severe or extreme drought, and they usually have a smaller index - and, thus, a smaller extension.

- The frequency of widespread episodes is almost the same at all timescales considered - widespread moderate moist episodes, even if they have smaller extent, occur at the four timescales analysed.

\section{Discussion and concluding remarks}

Extreme dry and wet events are usually disruptive events, and the associated impacts may differ considerably depending on the extent of the affected area. Research on weather and climate extremes has increased throughout the world, focusing on different spatial and temporal scales. Most studies are centred on the assessment of particular events, either from the impact study perspective (relevant for the development of risk assessment) or with the aim of understanding the physical mechanisms behind each of these events in order to attribute them to climate (natural or forced) variability or to climate change. Many works have been published over the last 2 decades covering these topics in Iberia, including the physical mechanisms of droughts (e.g. Garcia-Herrera et al., 2007; Trigo et al., 2013) or wet extremes (e.g. Vicente-Serrano et al., 2011; Liberato et al., 2012; Ramos et al., 2015; Hénin et al., 2021) and the impacts of these events (e.g. Gouveia et al., 2009, 2012; Trigo et al., 2016; Páscoa et al., 2017b; Ribeiro et al., 2019a).

However, a methodology for comparing extreme events is still missing. In this work, we present a simple yet robust methodology that is useful to rank extreme wet and/or dry events, considering both their magnitude and spatial extent that is, we present a tool that allows one to compare extremes, taking both the intensity and the area affected into account. Therefore, a method for ranking regional extremes of persistent, widespread drought and wet events is presented in this paper considering different timescales $(6,12,18$, and 24 months). The method is based on the multi-scalar Standardized Precipitation Evapotranspiration Index (SPEI) gridded dataset for the Iberian Peninsula for the 1901-2016 period.

The application of the methodology to indices at different timescales is another important aspect of this work. By jointly comparing the rankings of extreme events (both wet and dry) among different timescales more information may 
be obtained on the real extreme character of the events. For both the dry and wet periods, this tool allows for the identification of well-known regional extremes of persistent, widespread dry and wet periods at different timescales. Additionally, a comprehensive dataset of rankings of the most extreme, prolonged, widespread drought and wet periods in Iberia is built for 6-, 12-, 18-, and 24-month timescales, spanning the period from 1901 to 2016, using the multi-scalar SPEI gridded dataset with a regular resolution of $0.5^{\circ}$. This dataset will be available upon request for the following eight domains: the Iberian Peninsula, Portugal, and each of the six Iberian regions. Future work will be performed in the framework of current projects based on the identified most extreme events to better understand the common mechanisms behind each of these events.

We would like to stress that, to the best of our knowledge, this is the first and only paper to present a methodology to rank extreme (dry and wet) events in the IP. Once the methodology is established, it would be extremely interesting to study precisely how the ranking's positions compare when using other indices (such as the SPI or other impactbased indices that were not included in the construction of this methodology). This analysis will open new perspectives regarding the understanding of the dynamics behind the most extreme and widespread dry and wet events in the IP, as it is expected that the behaviour is different between wet and dry extremes. By applying this method to different regions and indices, research on the most extreme events may be developed worldwide.

Data availability. The rankings' datasets are publicly available at https://doi.org/10.6084/m9.figshare.13266440.v3 (Liberato et al., 2020) or on the project IMPECAF website (http://impecaf.rd. ciencias.ulisboa.pt/Ranking.html; IMPECAF, 2020). Please cite the article and database references. For further information, please contact the corresponding author.

Author contributions. AR performed the SPEI calculations and provided the SPEI datasets; IM performed the ranking calculations; MLRL, IM, and AR designed and made the figures; MLRL and CG designed the study and wrote the article; and all authors contributed to the interpretation and discussion of the results and the revision of the paper.

Competing interests. The authors declare that they have no conflict of interest.

Special issue statement. This article is part of the special issue "The 8th EGU Leonardo Conference: From evaporation to precipitation: the atmospheric moisture transport". It was presented at the 8th EGU Leonardo Conference, Ourense, Spain, 25-27 October 2016 .
Acknowledgements. This work was supported by national funds through FCT (Fundação para a Ciência e a Tecnologia, Portugal) and Portugal Horizon2020 under project WEx-Atlantic (PTDC/CTA-MET/29233/2017) and project UIDB/50019/2020 IDL. The authors acknowledge the editor and three anonymous reviewers for their pertinent comments that contributed to improving the paper.

Financial support. This research has been supported by the Fundação para a Ciência e a Tecnologia (project nos. PTDC/CTA-MET/29233/2017, PTDC/CTA-CLI/28902/2017, CEECIND/00027/2017, and UIDB/50019/2020-IDL).

Review statement. This paper was edited by José Marengo and reviewed by three anonymous referees.

\section{References}

Agnew, C. T.: Using the SPI to identify drought, Drought Netw. News, 12, 6-12, 2000.

Amraoui, M., Liberato, M. L. R., Calado, T. J., DaCamara, C. C., Coelho, L. P. Trigo, R. M., and Gouveia, C. M.: Fire activity over Mediterranean Europe based on information from Meteosat-8, Forest Ecol. Manag., 294, 62-75, https://doi.org/10.1016/j.foreco.2012.08.032, 2013.

Coll, J., Aguilar, E., and Ashcroft, L.: Drought variability and change across the Iberian Peninsula, Theor. Appl. Climatol., 130, 901-916, 2016.

Crausbay, S. D., Ramirez, A. R., Carter, S. L., Cross, M. S., Hall, K. R., Bathke, D. J., Betancourt, J.L., Colt, S., Cravens, A. E., Dalton, M. S., Dunham, J. B., Hay, L. E., Hayes, M. J., McEvoy, J., McNutt, C. A., Moritz, M.,A., Nislow, K. H., Raheem, N., and Sanford, T.: Defining Ecological Drought for the Twenty-First Century, B. Am. Meteorol. Soc., 98, 2543-2550, https://doi.org/10.1175/BAMS-D-16-0292.1, 2017.

DeSoto, L., Varino, F., Andrade, J. P., Gouveia, C. M., Campelo F., Trigo, R. M., and Nabais, C.: Different growth sensitivity to climate of the conifer Juniperus thurifera on both sides of the Mediterranean Sea, Int. J. Biometeorol., 58, 2095-2109, https://doi.org/10.1007/s00484-014-0811-y, 2014.

Domínguez-Castro, F, Vicente-Serrano, S. M., Tomás-Burguera, M, Peña-Gallardo, M., Beguería, S., El Kenawy, A., Luna, Y., and Morata, A.: High spatial resolution climatology of drought events for Spain: 1961-2014, Int. J. Climatol., 39, 5046- 5062, https://doi.org/10.1002/joc.6126, 2019.

Du, J., Fang, J., Xu, W., and Shi, P.: Analysis of dry/wet conditions using the standardized precipitation index and its potential usefulness for drought/flood monitoring in Hunan Province, China, Stoch. Environ. Res. Risk Assess., 27, 377-387, https://doi.org/10.1007/s00477-012-0589-6, 2013.

García-Herrera, R., Hernández, E., Barriopedro, D., Paredes, D.,Trigo, R. M., Trigo, I. F., and Mendes, M. A.: The Outstanding 2004/05 Drought in the Iberian Peninsula: Associated Atmospheric Circulation, J. Hydrometeorol., 8, 483-498, https://doi.org/10.1175/JHM578.1, 2007. 
González-Hidalgo, J. C., Vicente-Serrano, S. M., PeñaAngulo, D., Salinas, C., Tomas-Burguera, M., and Beguería, S.: High-resolution spatio-temporal analyses of drought episodes in the western Mediterranean basin (Spanish mainland, Iberian Peninsula), Acta Geophys., 66, 381-392 https://doi.org/10.1007/s11600-018-0138-x, 2018.

Gouveia, C., Trigo, R. M., and DaCamara, C. C.: Drought and vegetation stress monitoring in Portugal using satellite data, Nat. Hazards Earth Syst. Sci., 9, 185-195, https://doi.org/10.5194/nhess9-185-2009, 2009.

Gouveia, C. M., Bastos, A., Trigo, R. M., and DaCamara, C. C.: Drought impacts on vegetation in the pre- and post-fire events over Iberian Peninsula, Nat. Hazards Earth Syst. Sci., 12, 31233137, https://doi.org/10.5194/nhess-12-3123-2012, 2012.

Gouveia, C. M., Bistinas, I., Liberato, M. L. R., Bastos, A., Koutsiasd, N., and Trigo, R.: The outstanding synergy between drought, heatwaves and fuel on the 2007 Southern Greece exceptional fire season, Agr. Forest Meteorol., 218-219, 135-145, https://doi.org/10.1016/j.agrformet.2015.11.023, 2016.

Harris I., Jones, P. D., Osborn, T. J., and Lister, D. H.: Updated high-resolution grids of monthly climatic observations-the CRU TS3.10 Dataset, Int. J. Climatol., 34, 623-642, 2013.

Heim, R. R.: A Review of Twentieth-Century Drought Indices Used in the United States, B. Am. Meteorol. Soc., 83, 1149-1166, https://doi.org/10.1175/1520-0477-83.8.1149, 2002.

Hénin, R., Ramos, A. M., Pinto, J. G., and Liberato, M. L. R.: A ranking of concurrent precipitation and wind events for the Iberian Peninsula, Int. J. Climatol., 41, 1421-1437, https://doi.org/10.1002/joc.6829, 2021.

IMPECAF: Dataset, http://impecaf.rd.ciencias.ulisboa.pt/Ranking. html, last access: 22 December 2020.

Jerez S., Trigo R. M., Vicente-Serrano S. M., Pozo-Vazquez D., Lorente-Plazas R., Lorenzo-Lacruz J., Santos-Alamillos F., and Montavez J. P.: The Impact of the North Atlantic Oscillation on Renewable Energy Resources in Southwestern Europe, J. Appl. Meteorol. Clim., 52, 2204-2225, https://doi.org/10.1175/JAMCD-12-0257.1, 2013.

Jones, P. D. and Harris, I.: CRU TS3.21: Climatic Research Unit (CRU) Time-Series (TS) Version 3.21 of High Resolution Gridded Data of Month-by month Variation in Climate (Jan. 1901 - Dec. 2012), NCAS British Atmospheric Data Centre, 24th September 2013, https://doi.org/10.5285/D0E1585D-3417485F-87AE-4FCECF10A992, 2013.

Liberato, M. L. R.: The 19 January 2013 windstorm over the North Atlantic: large-scale dynamics and impacts on Iberia, Weather and Climate Extremes, 5-6, 16-28 https://doi.org/10.1016/j.wace.2014.06.002, 2014.

Liberato, M. L. R. and Trigo, R. M.: Extreme precipitation events and related impacts in Western Iberia, in: Hydrology in a Changing World: Environmental and Human Dimensions, IAHS Press, IAHS Red Book No 363, 171-176, 2014.

Liberato, M. L. R., Ramos, A. M., Trigo, R. M., Trigo, I. F., Durán-Quesada, A. M., Nieto, R., and Gimeno, L.: Moisture sources and large-scale dynamics associated with a flash flood event. In Lagrangian Modeling of the Atmosphere, edited by: Lin, J., Brunner, D., Gerbig, C., Stohl, A., Luhar, A., and Webley, P., pp. 111-126, Washington, DC, Am. Geophys. Union, https://doi.org/10.1029/2012GM001244, 2012.
Liberato, M. L. R., Pinto, J. G., Trigo, R. M., Ludwig, P., Ordóñez, P., Yuen, D., and Trigo, I. F.: Explosive development of winter storm Xynthia over the subtropical North Atlantic Ocean, Nat. Hazards Earth Syst. Sci., 13, 2239-2251, https://doi.org/10.5194/nhess-13-2239-2013, 2013.

Liberato, M. L. R., Ramos, A. M., Gouveia, C. M., Sousa, P., Russo, A., Trigo, R. M., and Santo, F. E.: Exceptionally extreme drought in Madeira Archipelago in 2012: Vegetation impacts and driving conditions, Agr. Forest Meteorol., 232, 195209, https://doi.org/10.1016/j.agrformet.2016.08.010, 2017.

Liberato, M. L. R., Montero, I., Gouveia, C. M., Russo, A., Ramos, A. M., and Trigo, R. M.: Dry and wet events - Rankings for Iberia, https://doi.org/10.6084/m9.figshare.13266440.v3, 2020.

Lionello P., Abrantes, F., Congedi, L., Dulac, F., Gacic, M., Gomis, D., Goodess, C., Hoff, H. Kutiel, H. Luterbacher, J., Planton, S., Reale, M., Schröder, K., Struglia, M. V., Toreti, A., Tsimplis, M., Ulbrich, U., and Xoplaki, E.: Introduction: Mediterranean Climate: Background Information, in: The Climate of the Mediterranean Region. From the Past to the Future, edited by: Lionello P., Elsevier, the Netherlands, Amsterdam,, XXXV-IXXX, ISBN: 9780124160422, 2012.

Macias-Fauria, M., Seddon, A. W. R., Benz, D., Long, P. R., and Willis, K.: Spatiotemporal patterns of warming, Nat. Clim. Change, 4, 845-846, 2014.

McKee, T. B. N., Doesken, J., and Kleist, J.: The relationship of drought frecuency and duration to time scales, Eight Conf. On Applied Climatology, Anaheim, CA, Amer. Meteor. Soc., 17-22 January 1993, 179-184, 1993.

Mitchell, T. D. and Jones, P. D.: An improved method of constructing a database of monthly climate observations and associated high-resolution grids, Int. J. Climatol., 25, 693-712, 2005.

Mukherjee, S., Mishra, A., and Trenberth, K. E.: Climate Change and Drought: a Perspective on Drought Indices, Curr. Clim. Change Rep., 4, 145-163, https://doi.org/10.1007/s40641-0180098-x, 2018.

New, M., Hulme, M., and Jones P.: Representing Twentieth-Century SpaceTime Climate Variability. Part II: Development of Monthly Grids of Terrestrial Surface Climate, J. Climate, 13, 2217-2238, 2000.

Palmer, W. C.: Meteorological drought, Research Paper No. 45, U.S. Department of Commerce Weather Bureau, Washington, D.C., 1965.

Páscoa, P., Gouveia, C. M., Russo, A., and Trigo, R. M.:The role of drought on wheat yield interannual variability in the Iberian Peninsula from 1929 to 2012, Int. J. Biometeorol., 61, 439-451, https://doi.org/10.1007/s00484-016-1224-x, 2017a.

Páscoa, P., Gouveia, C. M., Russo, A., and Trigo, R. M.: Drought Trends in the Iberian Peninsula over the Last 112 Years, Adv. Meteorol., 2017, 4653126, https://doi.org/10.1155/2017/4653126, 2017b.

Pereira, S., Ramos, A. M., Rebelo, L., Trigo, R. M., and Zêzere, J. L.: A centennial catalogue of hydro-geomorphological events and their atmospheric forcing, Adv. Water Resour., 122, 98-112, https://doi.org/10.1016/j.advwatres.2018.10.001, 2018.

Potopová, V., Štěpánek, P., Možný, M., Türkott, L., and Soukup, J.: Performance of the standardised precipitation evapotranspiration index at various lags for agricultural drought risk assessment in the Czech Republic, Agr. Forest Meteorol., 202, 26-38, 2015. 
Ramos, A. M., Trigo, R. M., and Liberato, M. L. R.: A ranking of high-resolution daily precipitation extreme events for the Iberian Peninsula, Atmos. Sci. Lett., 15, 328-334, https://doi.org/10.1002/as12.507, 2014.

Ramos, A. M., Trigo, R. M., Liberato, M. L. R., and Tomé, R.: Daily precipitation extreme events in the Iberian Peninsula and its association with Atmospheric Rivers, J. Hydrometeorol., 16, 579-597, https://doi.org/10.1175/JHM-D-14-0103.1, 2015.

Ramos, A. M., Trigo, R. M., and Liberato, M. L. R.: Ranking of multi-day extreme precipitation events over the Iberian Peninsula, Int. J. Climatol., 37, 607-620, https://doi.org/10.1002/joc.4726, 2017.

Ribeiro, A. F. S., Russo, A., Gouveia, C. M., and Páscoa, P.: Modelling drought-related yield losses in Iberia using remote sensing and multiscalar indices, Theor. Appl. Climatol., 136, 203-220, https://doi.org/10.1007/s00704-018-2478-5, 2019a.

Ribeiro, A. F. S., Russo, A., Gouveia, C. M., Páscoa, P., and Pires, C. A. L.: Probabilistic modelling of the dependence between rainfed crops and drought hazard, Nat. Hazards Earth Syst. Sci., 19, 2795-2809, https://doi.org/10.5194/nhess-192795-2019, 2019b.

Russo, A. C., Gouveia, C. M. Trigo, R. M. Liberato, M. L., and DaCamara, C. C.: The influence of circulation weather patterns at different spatial scales on drought variability in the Iberian Peninsula, Front. Environ. Sci., 3, https://doi.org/10.3389/fenvs.2015.00001, 2015.

Sorí, R., Vázquez, M., Stojanovic, M., Nieto, R., Liberato, M. L. R., and Gimeno, L.: Hydrometeorological droughts in the Miño-Limia-Sil hydrographic demarcation (northwestern Iberian Peninsula): the role of atmospheric drivers, Nat. Hazards Earth Syst. Sci., 20, 1805-1832, https://doi.org/10.5194/nhess20-1805-2020, 2020.

Spinoni, J., Naumann, G., Vogt, J., and Barbosa, P.: European drought climatologies and trends based on a multi-indicator approach, Global Planet. Change, 127, 50-57, 2015.

Stojanovic, M., Liberato, M. L. R., Sorí, R., Vázquez, M., PhanVan, T., Duongvan, H., Hoang Cong, T., Nguyen, P. N. B., Nieto, R., and Gimeno, L.: Trends and Extremes of Drought Episodes in Vietnam Sub-Regions during 1980-2017 at Different Timescales, Water, 12, 813, https://doi.org/10.3390/w12030813, 2020.

Sousa, J. J. and Bastos, L.: Multi-temporal SAR interferometry reveals acceleration of bridge sinking before collapse, Nat. Hazards Earth Syst. Sci., 13, 659-667, https://doi.org/10.5194/nhess13-659-2013, 2013.

Sousa, P. M., Trigo, R. M., Aizpurua, P., Nieto, R., Gimeno, L., and Garcia-Herrera, R.: Trends and extremes of drought indices throughout the 20th century in the Mediterranean, Nat. Hazards Earth Syst. Sci., 11, 33-51, https://doi.org/10.5194/nhess-11-332011, 2011.

Spinoni J., Antofie T., Barbosa P., Bihari Z., Lakatos M., Szalai S., Szentimrey T., and Vogt J.: An overview of drought events in the Carpathian Region in 1961-2010, Adv. Sci. Res., 10, 21-32, https://doi.org/10.5194/asr-10-21-2013, 2013.

Tao, H., Borth, H., Fraedrich, K., Suc, B., and Zhub, X.: Drought and wetness variability in the Tarim River Basin and connection to large-scale atmospheric circulation, Int. J. Climatol., 34, 2678-2684, https://doi.org/10.1002/joc.3867, 2015.
Trigo, R. M., Añel, J. A., Barriopedro, D., Garcia-Herrera, R., Gimeno, L., Nieto, R., Castillo, R., Allen, M. R., and Massey, N.: The record winter drought of 2011-2012 in the Iberian Peninsula, B. Am. Meteorol. Soc., 94, 41-45, 2013.

Trigo, R. M., Ramos, A. M., Pereira, S. Ramos, Zêzere, J., and Liberato, M. L. R.: The deadliest storm of the 20th century striking Portugal: Flood impacts and atmospheric circulation, J. Hydrol., 541, 597-610, https://doi.org/10.1016/j.jhydrol.2015.10.036, 2016.

van der Schrier, G., Briffa, K. R., Jones, P. D., and Osborn, T. J.: Summer moisture variability across Europe, J. Clim., 19, 28182834, 2006.

Vergni, L. and Todisco, F.: Spatio-temporal variability of precipitation, temperature and agricultural drought indices in central Italy, Agric. For. Meteor., 151, 301-313, https://doi.org/10.1016/j.agrformet.2010.11.005, 2011.

Vicente-Serrano, S. M.: Differences in spatial patterns of drought on different time scales: an analysis of the Iberian Peninsula, Water Resour. Manage., 20, 37-60, 2006.

Vicente-Serrano, S. M. and López-Moreno, J. I.: Hydrological response to different time scales of climatological drought: an evaluation of the Standardized Precipitation Index in a mountainous Mediterranean basin, Hydrol. Earth Syst. Sci., 9, 523-533, https://doi.org/10.5194/hess-9-523-2005, 2005.

Vicente-Serrano, S. M., Cuadrat-Prats J. M., and Romo A.: Early prediction of crop production using drought indices at different time-scales and remote sensing data: application in the Ebro Valley (northeast Spain), Int. J. Remote Sens., 27, 511-518, 2006.

Vicente-Serrano, S. M., Beguería, S., López-Moreno, J. I., Angulo, M., and El Kenawy, A.: A new global $0.5^{\circ}$ gridded dataset (1901-2006) of a multiscalar drought index: comparison with current drought index datasets based on the Palmer Drought Severity Index, J. Hydrometeorol., 11, 1033-1043, 2010a.

Vicente-Serrano, S. M., Beguería, S., and López-Moreno, J. I.: A Multi-scalar drought index sensitive to global warming: The Standardized Precipitation Evapotranspiration Index - SPEI, J. Clim., 23, 1696-1718, 2010b.

Vicente-Serrano, S. M., Trigo, R. M., Lopez-Moreno, J. I., Liberato, M. L. R., Lorenzo-Lacruz, J., Begueria, S., Moran-Tejeda, E., and El Kenawy, A.: The 2010 extreme winter North Atlantic Oscillation in Iberian precipitation: anomalies, driving mechanisms and future projections, Clim. Res., 46, 51-65, https://doi.org/10.3354/cr00977, 2011.

Vicente-Serrano, S. M., Beguería, S., Lorenzo-Lacruz, J., Camarero, J. J., López-Moreno, J. I., Azorin-Molina, C., Revuelto, J., Morán-Tejeda, E., and Sánchez-Lorenzo A.: Performance of drought indices for ecological, agricultural and hydrological applications, Earth Interact., 16, 1-27, 2012.

Vicente-Serrano, S. M., Gouveia, C., Camarero, J. J., Beguería, S., Trigo, R. M., López-Moreno, J. I., Azorín-Molina, C., Pasho, E., Lorenzo-Lacruz, J., Revuelto, J., Morán-Tejeda, E., and SanchezLorenzo, A.: Response of vegetation to drought time-scales across global land biomes, P. Natl. Acad. Sci. USA, 110, 52-57, https://doi.org/10.1073/pnas.1207068110, 2013.

Vicente-Serrano, S. M., Lopez-Moreno, J. I., Beguería, S., LorenzoLacruz, J., Sanchez-Lorenzo, A., García-Ruiz, J. M., AzorinMolina, C., Morán-Tejeda, E., Revuelto, J., Trigo, R. M., Coelho, F., and Espejo, F.: Evidence of increasing drought severity caused 
by temperature rise in southern Europe, Environ. Res. Lett., 9, 044001, https://doi.org/10.1088/1748-9326/9/4/044001, 2014.

Vicente-Serrano, S. M., Quiring, S. M., Peña-Gallardo, M., Yuan, S., and Domínguez-Castro, F.: A review of environmental droughts: Increased risk under global warming?, Earth-Sci. Rev., 201, 102953, https://doi.org/10.1016/j.earscirev.2019.102953, 2020a.

Vicente-Serrano, S. M., Domínguez-Castro, F., Murphy, C., Hannaford, J., Reig, D., Peña-Angulo, F., Tramblay, Y., Trigo, R. M., Mac Donald, N., Luna, M. Y., Mc Carthy, M., Van der Schrier, G., Turco, D., Camuffo, M., Noguera, I., García-Herrera, R., Becherini, F., Della Valle, A., Tomas-Burguera, M., and El Kenawy, A.: Long-term variability and trends in meteorological droughts in Western Europe (1851-2018), Int. J. Climatol., 2020, 1-28, https://doi.org/10.1002/joc.6719, 2020b.

Wells, N., Goddard, S., and Hayes, M. J.: A self-calibrating Palmer Drought Severity Index, J. Clim., 17, 2335-2351, 2004.
Wilhite, D. A.: Drought Assessment, Management and Planning: Theory and Case Studies, Kluwer Academic Publishers, New York, 293 pp., 1993.

WMO: Drought monitoring and early warning: concepts, progress and future challenges, WMO-No. 1006, 2006, World Meteorological Organization, ISBN 92-63-11006-9, available at: http: //www.wamis.org/agm/pubs/brochures/WMO1006e.pdf (last access: 19 March 2020), 2006.

Wu, H., Svoboda, M. D., Hayes, M. J., Wilhite, D. A., and Wen, F.: Appropriate application of the Standardized Precipitation Index in arid locations and dry seasons, Int. J. Climatol., 27, 65-79, https://doi.org/10.1002/joc.1371, 2007.

Zêzere, J. L., Trigo, R. M., and Trigo, I. F.: Shallow and deep landslides induced by rainfall in the Lisbon region (Portugal): assessment of relationships with the North Atlantic Oscillation, Nat. Hazards Earth Syst. Sci., 5, 331-344, https://doi.org/10.5194/nhess-5-331-2005, 2005. 